\title{
Etnografias em contextos pedagógicos: alteridades em jogo
}

\author{
EVA SCHELIGA \\ UNIVERSIDADE FEDERAL DO PARANÁ (UFPR), CURITIBA/PR, BRASIL \\ HTTP://ORCID.ORG/0000-0002-2270-0636
}

JULIANE BAZZO

UNIVERSIDADE FEDERAL DA GRANDE DOURADOS (UFGD), DOURADOS/MS, BRASIL

HTTPS://ORCID.ORG/OOOO-OOOI-6Ig6-3482

É com contentamento que fazemos chegar ao público leitor da Campos o segundo conjunto de artigos do dossiê Etnografias em contextos pedagógicos. O foco de atenção desse novo apanhado de textos dirige-se aos marcadores sociais da diferença, em suas variadas manifestações nos ambientes formais de ensino. Junto de Almeida et al. (2018:19), entendemos tais diacríticos "como efeito da operação de complexos sistemas de conhecimento e de relações sociais".

Logo, delimitados coletivamente, os marcadores não são naturais, mas podem surgir naturalizados e, muitas vezes, interseccionados (Crenshaw, 2002) para encampar exclusões e violações em contextos atravessados por múltiplas e profundas iniquidades, como a realidade educacional do Brasil. Ao mesmo tempo, essas alteridades e suas articulações mobilizam, na contramão, agências dos sujeitos que as corporificam, impulsionando abundantes processos de subjetivação, negociação e ação política conjugada, pela dissolução de cenários de desigualdade e pela afirmação da justiça social.

Conforme balanço realizado por Simões (2018), os marcadores sociais da diferença figuram enquanto segunda área que mais cresceu em linhas de pesquisa na Antropologia brasileira na primeira década dos 2000, situando-se atrás apenas do tradicional campo de investigações sobre identidade, territórios e relações interétnicas. Esse robustecimento encontra origens na consolidação, verificada nos anos 1990, dos chamados Estudos de Gênero, cujo cabedal teórico vai colaborar, sobremaneira, com reflexões mescladas sobre diacríticos de alteridade, conectando, dessa forma, gênero, sexualidade, raça e classe nas análises, mas também outros, como geração (Debert, 2010) e deficiência (Mello, 2019).

Não surpreende que a expansão dos marcadores sociais da diferença como temática investigativa tenha repercutido sobre uma Antropologia da Educação contemporânea que toma os espaços 
formais de ensino enquanto universos empíricos privilegiados de estudo (Bazzo \& Scheliga, 2020). Segundo Pereira (2017: 169), se o modus operandi das instituições de ensino modernas se dá em favor da naturalização de um panorama de subalternidades, opressões e violências, "há também muitas amostras de como elas [as entidades educacionais] são espaços em que as diferenças são colocadas em questão a todo momento".

Justamente pela característica de reservatório de alteridade, Frigotto (2001) argumenta que a "gestão da escola" é "historicamente problemática" para o projeto de poder hegemônico: o capitalismo moderno-ocidental necessita dela como instituição para ampliar a mão de obra e controlar o saber, entretanto o acesso sucessivamente democratizado ao conhecimento, ainda que precarizado, termina por abastecer articulações sociais a desafiar o próprio sistema. Os ambientes educacionais formais são assim, a um só tempo, lugares de luta e de esperança por transformação (Sallas, 2017).

A seguir, antes de apresentar os artigos deste número, justamente instigadas pela riqueza de discussões que suscitam, problematizamos duas temáticas que nos são caras enquanto frentes particulares de pesquisa no cenário brasileiro - a Primavera Secundarista, para a segunda autora e a religiosidade em instituições de ensino, para a primeira. Acreditamos que ambos os assuntos nos possibilitam evidenciar, empiricamente, a ambivalência acima referida, entre subalternização e insurgência na operação institucional da escola, oscilação em que as diferenças e suas ebulições exercem papel crucial.

\section{Ocupações estudantis: um marco e seu legado}

A chamada Primavera Secundarista, desenrolada no Brasil entre os anos de 2016 e 2017, situa-se enquanto um "drama social” (Turner, 2008 [1974]) contemporâneo exemplar desse paradoxo (Rede Escola Pública e Universidade, 2019). Como sabido, esse movimento de estudantes manifestou-se contra o sucateamento da educação pública brasileira a partir das chamadas ocupações em escolas de várias partes do território nacional, sob especial inspiração de uma experiência discente dessa ordem sediada no Chile, em 2006, denominada de Revolta dos Pinguins.

Por aqui, a Primavera veio na esteira de uma série de políticas e programas progressistas, em favor da inclusão econômica e do reconhecimento da diversidade sociocultural, sob a liderança dos governos petistas à frente do poder executivo. Como abordamos em outro lugar (Bazzo \& Scheliga, 2020), esse conjunto de intervenções estatais encontrou no campo da educação um espaço central para efeitos democratizadores. Estes, contudo, se viram às voltas com seus limites diante da onda conservadora que contra eles se insurgiu e que propulsionou os protestos estudantis.

Em nosso país, as ocupações principiaram em São Paulo quando, no final de 2015, o governo do Estado anunciou uma "reorganização escolar" que, na prática, fecharia instituições de ensino e remanejaria à revelia discente contingentes do alunado. O levante paulista impulsionou coletivos de estudantes em outras unidades federativas, cujas mobilizações se intensificaram diante da impopularidade da reforma do Ensino Médio suportada pelo Governo Michel Temer, logo após o impeachment controver- 
so da presidenta Dilma Rousseff. A contestação questionou o caráter autoritário, apressado, retrógrado e elitista da proposta reformista, colocada em curso por medida provisória (Carvalho et al., 2019) ${ }^{1}$.

Em depoimentos acerca da memória das ocupações, alunas do Colégio Pedro II, instituição de ensino público federal situada no Rio de Janeiro (RJ), sintetizam que esses acontecimentos se fizeram em torno de "três pilares" - "pretos" - sustentadores do cotidiano escolar: a limpeza, a alimentação e a segurança. Na experiência de ocupar, tais atividades foram, nas palavras delas, "curricularizadas", dado que sua gestão ficou a cargo de coletivos de estudantes. Esse processo permitiu ao alunado dar-se conta de que a escola pública não se realiza apenas por discentes e docentes, mas pelos esforços conjugados de uma série de outras(os) trabalhadoras(es), em parte considerável terceirizadas(os), mulheres e negras(os) (The Intercept, 2019).

Afora essas atividades de base, o dia a dia das ocupações ficou marcado por uma gama de assembleias, rodas de conversa, oficinas e aulas abertas, nas quais se somaram convidadas(os) externas(os) às comunidades escolares, entre militantes, intelectuais e artistas. Esse cotidiano não foi "fácil" ou "linear", pois se as(os) estudantes receberam apoio de colegas, docentes, gestores escolares e familiares, também encontraram oposições advindas dessas mesmas categorias de atores, às quais se adicionaram tentativas de repressão policial e de outros órgãos estatais (Rede Escola Pública e Universidade, 2019).

A despeito disso, momentos potentes de diálogo resistiram e, afora as discussões logísticas do movimento, as(os) discentes colocaram em debate um rol de questões contemporâneas de seu interesse, sobre gênero, sexualidade, feminismo, homofobia, racismo e violência (Sallas, 2017; Carvalho et al., 2019). Nesse panorama, contestaram-se as investidas do movimento conservador Escola sem partido, com seus riscos e efeitos, hoje publicamente reconhecidos, de criminalização da atuação docente, na contramão da liberdade de cátedra; de tolhimento do pensamento crítico entre estudantes; bem como de obstáculos a discussões amplificadas na escola sobre diversidade e direitos de minorias políticas (United Nations Human Rights, 2017)2.

Grandemente midiatizada, graças ao poderio das redes sociais virtuais, a Primavera Secundarista teve entre seus méritos a capacidade de suspender na esfera pública um discurso de precariedade e imobilismo não raro empregado para caracterizar a educação pública brasileira (Guedes, 2014; Sallas, 2017). O movimento apresentou à sociedade, por conseguinte, vozes em direção oposta, plenas de força política, luta por cidadania e desejo por projetos de futuro, materializadas na escola, com ela e a partir dela. Como assinalam Carvalho et al. (2019: 256), em linha com o pensamento turneriano, as ocupações constituíram "communitas", uma "experiência de unidade": "todos e cada um eram a escola e a escola era a comunidade da ocupação".

1 Embora o governo anunciasse que a reforma propiciaria mais liberdade e oportunidades para o alunado, seus críticos desaprovavam nela a promoção da mercantilização educacional, o favorecimento de um percurso de formação determinado por origens sociais e, por fim, o aprofundamento de desigualdades, em direção a uma intensificação do neoliberalismo no país. A Associação Nacional de Pós-Graduação e Pesquisa em Educação (Anped) manifestou-se publicamente sobre isso em mais de uma ocasião. Para tanto, $c f$. www.anped.org.br.

2 Capitaneado por uma organização da sociedade civil, o Escola sem partido diz militar contra a "usurpação do direito dos pais dos alunos sobre a educação moral dos seus filhos", além de combater o que chama de "contaminação político-ideológica" - de esquerda - nas salas de aula do país, lançando mão para isso de vias não só midiáticas, mas também legais, na forma de projetos de lei ( $c f$. www.escolasempartido.org). 
Nessa vivência liminar, as alteridades mostraram-se recrutadas a todo momento, seja para evidenciar como são transformadas em desigualdades e violências materiais e existenciais (Therborn, 2010), seja enquanto catalisadoras de subjetivação, agência e insurgência (Almeida et al., 2018). Aniely Silva (2019: 187, 191) - jovem que se define como uma mulher negra, lésbica, periférica, feminista e ativista da educação, além de acadêmica de ciências sociais - bem sintetiza como assim veio a se reconhecer, especialmente no que tange à afirmação de sua sexualidade, a partir do engajamento em uma ocupação de São Paulo (SP):

A escola é o lugar onde as pessoas podem finalmente ser quem elas são e conquistar o seu espaço. É o lugar onde os maiores conflitos das descobertas pessoais aparecem. E como é assustador. [...] Acabei entendendo que os problemas que eu tinha não eram necessariamente de "comportamento” ou de assimilação de conteúdo. Eram parte da descoberta de quem eu sou. Não tive ajuda em casa e nem na escola [antes da ocupação], até ver pessoas que, assim como eu, não sabiam o que fazer, mas estavam dispostas a se ajudar no que fosse preciso. Construímos juntos a nossa concepção de escola e de nós mesmas, e foi transformador.

A natureza catártica das ocupações, entretanto, chocou-se com uma espiral conservadora, que já estava no pano de fundo dos levantes estudantis e terminou por desmobilizá-los. Como decorrência, reivindicações importantes do movimento não se fizeram atendidas como, por exemplo, o recuo da reforma do Ensino Médio, que acabou concretizada na Lei ${ }^{\circ}$. $13.415 / 2017$. A despeito do desconcerto e da frustração que se abateram entre as(os) estudantes partícipes, principalmente diante da chegada ao poder de um governo de extrema-direita nas eleições de 2018 (Capai, 2019), há que se concordar com Carvalho et al. (2019: 258) quando afirmam que "[a]o suceder a antiestrutura, a estrutura já não é a mesma”.

Nas repercussões de longa duração da Primavera, nas aprendizagens que propiciou mobilizando e projetando alteridades diversificadas, bem como nas marcas subjetivas, identitárias e políticas indeléveis que deixou, recordamos o esperançar de Butler (2017):

O mundo que os conservadores querem destruir, o mundo gay e lésbico, o mundo trans, o mundo feminista, já é muito poderoso. Eles não têm nenhuma chance de destruí-lo. E eles realmente sabem que não apenas é muito poderoso, como está se tornando mais poderoso, está se tornando mais aceito, e quanto mais aceito é, com mais raiva eles ficam. Mas o que vemos agora, nesse conservadorismo sexual contemporâneo, ou o que podemos entender como política sexual reacionária, é um esforço para nos levar de volta a um mundo que nunca mais voltará.

\section{Religião: um marcador de diferença por toda parte na escola}

No complexo jogo das alteridades vislumbrado nos contextos pedagógicos, a religião tem ocupado um lugar central - ainda que nem sempre seja um marcador de diferença analisado em conjunto com a tríade gênero, classe e raça mais comumente abordada no bojo de uma perspectiva interseccional. Considerando os dados dos artigos reunidos neste dossiê, é notável o quanto a declaração de filia- 
ção religiosa de docentes e discentes, bem como a maior ou menor adesão desses agentes aos princípios da laicidade, da liberdade de crença e de expressão de diferenças, atravessam as experiências escolares, constituindo-as e também por elas sendo informadas.

Em muitos casos, as filiações religiosas têm levado ao acirramento de conflitos e a práticas segregadoras no âmbito das instituições de ensino (Miranda, 2015), projetando-se nas escolas dinâmicas que só podem ser melhor compreendidas à luz das mudanças recentes do cenário (religioso e político) nacional. Em concomitância aos conflitos, também se vislumbra a criação, através das religiões, de laços potentes: além da organização de redes e circuitos de sociabilidade nas escolas e para além delas, a vivência religiosa conforma sensibilidades específicas e abre possibilidades de ação que, de outro modo, não poderiam ser efetivadas por estudantes - e também por seus familiares, por docentes e funcionárias(os) das escolas. As relações entre escola, educação e religião são marcadas, pois, por ambiguidades, bem como por inúmeras clivagens, considerando-se a profunda heterogeneidade no interior dos grupos religiosos que orbitam as instituições de ensino. Assim, é preciso redobrarmos a cautela para efetivamente avançarmos a compreensão sobre o processo de produção e realocação das diferenças via religião.

O entendimento sobre as mudanças no "campo religioso" brasileiro e sua reverberação nas dinâmicas escolares - e vice-versa, já que as instituições de ensino também se constituem como espaços criativos, nos quais novas formas de experimentação religiosa se processam, tensionando o modo "tradicional" como as religiões se configuram no espaço público -, incitam, por certo, a novas pesquisas. Há, contudo, um importante caminho que já vem sendo trilhado em tal direção, sendo oportuno registrar, neste texto, alguns marcos importantes deste debate. No Brasil a presença do religioso no espaço escolar tem sido problematizada especialmente a partir da análise da oferta de aulas de Ensino Religioso (ER) no Fundamental II. Foi sobretudo na década de 2000, sob os auspícios do Instituto Superior de Estudos da Religião (ISER), que pesquisas sobre esta disciplina de oferta obrigatória, porém de matrícula facultativa, ganharam particular destaque no âmbito das Ciências Sociais.

O escrutínio da noção de laicidade e seu agenciamento em espaços públicos (neste caso específico, as escolas) norteou uma investigação antropológica pioneira organizada por Emerson Giumbelli em parceria com Sandra de Sá Carneiro. Em um conjunto de publicações, editadas a partir de 2004, a dupla divulgou os resultados da pesquisa que envolveu o mapeamento do ensino religioso no país, trazendo considerações sobre os marcos legais e conteúdos curriculares (Carneiro, 2014; Giumbelli, 2009a, 2009b, 2011; Giumbelli \& Carneiro, 2004 e 2006).

Pesquisas com foco nas aulas de ER e nas inúmeras controvérsias que envolvem sua implantação nas escolas públicas têm sido fundamentais para a sistematização de um corpo de reflexões a respeito dos processos de negociação do princípio da laicidade na história de nossa República. Igualmente lançam luz sobre os meandros da formação docente e a respeito da autonomia da instituição escolar frente a autoridades não seculares. Vale destacar que aos esforços de Giumbelli e de Carneiro somam-se os de Dickie \& Lui (2007), Lui (2007, 2014), Braga (2008), Ranquetat Jr. (2008), Diniz, Lionço \& Carrião 
(2010), Maia (2014), Miranda \& Maia (2014), Miranda (2015), Rodrigues (2015) e Santos (2016), para citar apenas alguns trabalhos ${ }^{3}$.

$\mathrm{O}$ enfoque conferido à entrada da religião nos currículos escolares (inicialmente via disciplina de ER) continua sendo relevante, sobretudo em meio à implantação da Base Nacional Comum Curricular (BNCC) - documento que estabelece as competências específicas, as unidades temáticas, os objetos de conhecimento e as habilidades a serem desenvolvidas no âmbito das disciplinas - e, com ela, do surgimento de um novo componente curricular transversal, os assim chamados "projetos de vida", no Ensino Médio. Os modos específicos de circulação de categorias religiosas na composição de propostas orientadas à reflexão e à tomada de decisões por parte de jovens estudantes, em articulação com as discussões previstas sobre "autoconhecimento" e "ascensão social e profissional", sem dúvida passam a requerer a atenção das(os) pesquisadoras(os) que tomam os contextos pedagógicos como centro de suas etnografias.

Outro elemento que deve ser levado em consideração é a repercussão da decisão de 2017 do Supremo Tribunal Federal (STF) sobre a improcedência da Ação Direta de Inconstitucionalidade (ADI) $n^{\circ}$ 4.439. Nela a Procuradoria-Geral da República questionava o modelo de ensino religioso contrário à exposição neutra das religiões, entendendo que o ensino confessional feriria o princípio da laicidade do Estado; por decisão apertada (foram seis votos a cinco), estabeleceu-se, contudo, que o ensino religioso ministrado nos estabelecimentos públicos de ensino pode ter caráter confessional ${ }^{4}$. Os efeitos desta decisão continuam sendo vislumbrados, não apenas no que diz respeito ao ensino religioso confessional, mas também no debate mais geral sobre os modos pelos quais as diferenças podem ou não ser suprimidas no regime de uma educação pública. No limite, pois, é a própria redefinição do caráter de uma educação pública que vem sendo objeto de disputa. Não por acaso, vemos ressurgir com força o debate sobre homeschooling, modalidade de ensino que outorga aos pais o direito de promover a educação, sem um necessário vínculo com a escola 5 .

Não se pode perder de vista, contudo, que a religião não vai à escola apenas como conteúdo curricular: ela adentra os muros da escola de inúmeros outros modos, pois integra um esquema de percepção e apreciação do mundo acionado pelos(as) agentes em meio às mais diversas experiências e relações que perpassam as instituições escolares. Já se acumulam, neste sentido, investimentos de pesquisa que exploram variados nexos entre religião e educação. Dentre eles, remetemos à leitura dos

3 Uma lista ampliada da bibliografia sobre ensino religioso encontra-se disponível na página do Núcleo de Estudos da Religião (NER) da Universidade Federal do Rio Grande do Sul (http://www.ufrgs.br/ner/index.php/estante/arquivo-a-campo/48-bibliografia-ensino-religioso). Uma relação - desatualizada, porém útil - de teses sobre o tema pode, por sua vez, ser encontrada na página do Observatório da Laicidade do Estado (OLÉ): http://www.nepp-dh.ufrj.br/ole/teses-ens_rel.html

4 Seguiram o parecer do relator do processo, Luis Roberto Barroso, que se manifestou favorável à ADI, os ministros Celso de Mello, Marco Aurélio, Luiz Fux e Rosa Weber. Foram contrários ao parecer os ministros Gilmar Mendes, Ricardo Lewandowski, Dias Toffoli, Edson Fachin, Alexandre de Moraes e Carmen Lúcia, que deu o voto de minerva. Embora não seja possível desenvolver no espaço deste texto a teia de argumentos favoráveis e contrários aos modelos de ensino religioso, não nos furtamos a destacar que na decisão colegiada acabou por prevalecer a compreensão de que o ensino religioso aconfessional desrespeitaria alunos e suas famílias, obrigando-os a entrar em contato com ideias contrárias às suas; ou seja, vigorou um entendimento sobre religião enquanto direito subjetivo individual, não cabendo ao Estado, segundo maioria dos Ministros do STF, interferir nesta escolha.

5 Desde 2001 há registros de projetos de lei que visam regulamentar o homeschooling, sem sucesso na tramitação. Bandeira de campanha do atual Presidente da República, a educação domiciliar foi incluída no rol das 35 prioridades do governo. No momento em que redigimos este texto, o PL 3262/19, apresentado em 3 de junho de 2019, entrou na pauta da Comissão de Constituição e Justiça e de Cidadania na Câmara Federal. 
trabalhos conduzidos por Roberta Bivar Campos e equipe (Campos et al., 2010; Campos \& Silva, 2011; Silva \& Campos, 2011) no âmbito de um projeto sobre (in)tolerância religiosa em escolas públicas e privadas de Recife, desenvolvido entre 2007 e 2009, e às recentes pesquisas de Alana Braga de Souza (2016), Luciana Silva (2019) e de Marina Minarelli (2020) que, em comum, tiveram por foco de análise a presença evangélica em escolas públicas, respectivamente em Abreu e Lima, Juiz de Fora e em São Paulo. Mencionamos também as pesquisas produzidas no campo da Educação, em diálogo com perspectivas sociológicas, elaboradas por Denise Mak (2014), Gabriela Valente (2015) e Adriane Knoblauch (2015) sobre formação docente e vínculos religiosos ${ }^{6}$.

Esta literatura dá visibilidade a diversas situações que indicam como as religiões, de modo explícito ou oculto, compõem a paisagem escolar. Uma delas é a forma como muitas equipes pedagógicas e docentes organizam suas rotinas diárias: não é incomum ler menções feitas a gestoras(es), membros da equipe pedagógica e/ou docentes dando início ou encerrando suas rotinas diárias com a convocação de estudantes para recitarem orações (Braga, 2008). O chamado às orações abrangeria desde preces cristãs padronizadas, como é o caso do pai-nosso ou da oração do Santo Anjo, até rezas de caráter mais espontâneo e subjetivo, refletindo diferentes modalidades de relações estabelecidas com entes divinos ou sobrenaturais.

Também são frequentes os relatos acerca da presença de símbolos religiosos nos recintos escolares públicos, tanto nos espaços administrativos, ocupados estritamente por funcionárias(os) do estabelecimento de ensino, quanto nos de uso coletivo destinados prioritariamente a estudantes, como salas de leitura e refeitórios. Outro exemplo relaciona-se ao calendário escolar, marcado por feriados e celebrações de caráter religioso. À primeira vista, podemos inferir que ocorre a naturalização de algumas datas, como notadamente é o caso dos ciclos festivos da Páscoa e do Natal (Mak, 2014; Silva, 2011; Silva \& Campos, 2011) - e que, assim como a oração do pai-nosso e alguns símbolos cristãos, como a cruz e a bíblia (Ranquetat Jr., 2012), são assumidas como universais e, portanto, de interesse compartilhado por todos os membros da comunidade escolar.

Minarelli (2020), no entanto, nos mostra outro ângulo deste quadro: a adesão às festividades muitas vezes exige a "flexibilização das crenças" de estudantes e, especialmente, de seus responsáveis, em uma complexa avaliação que observa os potenciais ganhos e riscos em participar, ou não, dos eventos com conotações religiosas. Em cada etapa da vida estudantil é possível (re)considerar as oportunidades de aprendizagem e de sociabilidade que as festas acarretam, de modo que o "peso" da religião é ponderado, caso a caso. A mesma criança que, em um ano escolar, foi autorizada a participar de uma celebração que contraria seu código religioso pode, em outro, ser formalmente proibida de envolver-se com a festa - interdição que pode ou não ser seguida, lembrando aqui das avaliações feitas pelos(as) estudantes e das possibilidades de agência que lhes são próprias.

Além disso, a literatura pontua que nem todas as celebrações são bem-vindas nos contextos pedagógicos cada vez mais diversos em termos religiosos. Algumas práticas de devoção, como a que envolve

6 Além das referidas pesquisas, vale fazer menção a surveys realizados em instituições de Ensino Superior, públicas e privadas, visando traçar o perfil religioso de estudantes de graduação e/ou as conexões entre pertencimento religioso, engajamento acadêmico e envolvimento com atividades filantrópicas e políticas. Um levantamento destes estudos pode ser encontrado em Scheliga, Knoblauch e Bellotti (2020). 
a distribuição de doces no dia de São Cosme e Damião, nas últimas décadas passaram a ser sistematicamente recusadas, e com veemência, por estudantes e docentes em alguns contextos (L. Silva, 2019). Assim, reitera-se na escola (e/ou se constrói, a partir dela) uma oposição entre, de um lado, católicos e praticantes de religiões afro-brasileiras e, de outro, as pessoas que se declaram evangélicas - divisão que logo em seguida pode sofrer rearranjos se mudarmos o objeto de controvérsia.

É possível observar, pois, a série de disputas e a consequente elaboração de novos sentidos a alguns festejos, como é o caso emblemático das celebrações juninas. Ao longo dos últimos anos diversos estabelecimentos de ensino aboliram os festejos dedicados ao trio dos assim chamados santos juninos (Santo Antônio, São João e São Pedro) e, em substituição, passaram a celebrar as "festas da colheita" ou a "festa junina da roça". Tais reformulações atenderiam a uma demanda pela inclusão nos festejos de outras confissões religiosas, evitando gerar constrangimentos nos alunos e alunas não professantes da fé católica. Tais transformações também estariam vinculadas a demandas específicas de docentes e membros de equipes gestoras e pedagógicas de confissão não católica, interessados em evitar o contato (ou contágio) com o universo dos santos católicos.

Se, por um lado, a requalificação das festas juninas tem potencial para apaziguar certos conflitos religiosos, por outro, tal procedimento também pode gerar outras tantas rusgas. Manifestações de descontentamentos em relação à transformação do que se convenciona chamar de "tradições escolares" ou, ainda, do que se assume como símbolo da "cultura nacional" - no caso, o catolicismo popular - ou do folclore brasileiro, com a mobilização da noção de multiculturalidade para promover a diversidade religiosa no âmbito do ensino (Silva \& Campos, 2011) também surgem aqui e ali nos diálogos travados entre pesquisadores(as) e docentes, por exemplo.

As festas juninas - e outras datas cívicas, tais como o Dia da Consciência Negra (como nos mostra L. Silva, 2019 e Oliveira \& Nascimento, neste número) - são, neste sentido, eventos particularmente férteis para observarmos as tensões e negociações em torno de duas políticas. Uma, segundo a qual as diferenças devem ser minimizadas ou mesmo suprimidas a favor de uma expressão supostamente neutra que seja capaz de funcionar como denominador comum, como um código compartilhado (seja por conta de uma determinação legal ou por motivações religiosas comuns a diversos integrantes da comunidade escolar). Outra, que reivindica o destaque e a valorização da identidade social de grupos específicos, envolvendo seus códigos particulares ${ }^{7}$.

Todos os exemplos citados até aqui nos permitem inferir, pois, uma hierarquia oculta de crenças, sendo notória a prevalência de uma determinada matriz de pensamento religioso - de orientação cristã - e pouca abertura às demais manifestações religiosas. A este respeito podemos citar um exemplo oriundo do trabalho de Gabriela Valente (2015). Em uma atividade rotineira com sua turma do Ensino Fundamental, Raquel, uma das interlocutoras de Valente, deliberadamente interrompeu a programação de leitura do capítulo final de uma história cuja heroína era a orixá Iemanjá. Inicialmente a pesquisadora supôs que a interrupção da atividade derivava do entendimento de Raquel de que "a escola é laica”, ou seja, de que não seria oportuno dar destaque à temática religiosa naquele espaço

7 As festas juninas também se mostram centrais nas políticas de diferença de gênero empreendidas nos contextos pedagógicos. A este respeito, ver o artigo de Nascimento \& Figueiredo (2021), publicado nesta edição do dossiê. 
público. Contudo, não era este o caso: ao ser questionada sobre a mudança na condução da atividade, a professora confirmou à pesquisadora que receava tratar de questões relativas às religióes africanas e afro-brasileiras no contexto escolar, pois nas palavras de Raquel, "havia [na história] coisas estranhas, de macumba" (Valente, 2015: 55/56 - grifos da autora). Assim, posiciona-se em claro desacordo com o que estabelece a Lei 10.639/2003 que tornou obrigatório o ensino de História da África e cultura afro-brasileira.

Além das orações regulares marcando os tempos escolares, das disputas em torno do significado das festas e dos símbolos religiosos e da nada incomum presença de agentes religiosos compondo a gestão escolar, mencionamos outras situações que evidenciam como a religião se faz presente no cotidiano escolar. Tomamos aqui o que nos indica Bérengère Massignon (2000) tendo como referência o contexto educacional francês. Um primeiro exemplo diz respeito a dar ou não atenção a regimes de obrigações alimentares específicas em virtude de pertencimentos religiosos, resultando na modificação dos cardápios das merendas e refeições servidas a estudantes e profissionais de educação - o que também nos remete ao trabalho de L. Silva (2019) que abordou situações envolvendo evitações, por parte de distintos agentes da escola, à comensalidade com conotação religiosa. Outros exemplos referem-se à adoção de uma política de maior ou menor tolerância ao absenteísmo justificado por pertencimentos religiosos, bem como à organização de capelanias religiosas e de modos de prestação de assistência religiosa aos usuários de equipamentos socioeducativos, envolvendo maior ou menor diversificação dos tipos de serviço religioso oferecidos nestes espaços.

Em comum, todas as situações indicam como as instituições de ensino são, o tempo todo, instadas a colocar em marcha uma série de medidas que ora constrangem, ora ampliam os limites do religioso. A decisão do STF acerca do ensino religioso confessional bem exemplifica a querela em torno da religião, mas não é, de modo algum, a única situação que permite antever a ambivalência do Estado frente ao fenômeno religioso: norteado pelo princípio da laicidade, compete ao Estado garantir meios para o exercício de identificação e compreensão das diferenças enquanto tais e, neste sentido, deve tornar a religião um objeto de reflexão e de tolerância, concedendo tratamento equânime a todas as crenças; também cabe ao Estado laico garantir a liberdade de culto e de crença, garantindo o exercício dos direitos individuais. A escola pública, integrando a malha do Estado, configura-se, assim, como um espaço social singular no qual estes preceitos são postos em ação e estes antagonismos são vividos; torna-se, assim, um campo privilegiado para se observar como as religiões (e também a própria noção de laicidade) são produzidas e modeladas, ou seja, sobre o que é socialmente definido como possível de ser classificado e aceito como religioso - e o que escapa a estes limites, e como.

Colocar sob a lupa das Ciências Sociais e, sobretudo, da Antropologia, toda esta gama de práticas que estruturam o cotidiano escolar produz um deslocamento interessante, a nosso ver. Somos convidados(as) a observar e analisar mais detidamente os processos históricos e as condições sociais que constituem o religioso e o laico em nossa sociedade e, por consequência, a revisitar criticamente alguns pressupostos acerca do retraimento do religioso na modernidade. 


\section{Os artigos do número}

Em seu conjunto, acreditamos que os artigos a compor esta segunda parte do dossiê Etnografias em contextos pedagógicos colaboram na reflexão antropológica sobre nuances a permear determinantemente o universo de debate dos marcadores sociais da alteridade. $\mathrm{O}$ mapeamento dessas sutilezas, por intermédio do esforço etnográfico, nos defronta com a existência - não estanque e sim dinâmica - de diferenças no interior das diferenças, conforme o desenho de certas conjunturas sócio-históricas, no Brasil e no mundo.

Esse encontro se revela propício ao adensamento tanto teórico-empírico, quanto político-militante, de questões nevrálgicas, como aquelas a respeito da "interseccionalidade" (Crenshaw, 2002; Akotirene, 2018); de "batalhas morais" na esfera pública em torno das identidades (Miskolci, 2020); como também daquilo que se denomina por "allyship" ["aliança”] no panorama dos ativismos estadunidenses. Esta última ideia refere-se às possibilidades de engajamento efetivo, não superficial ou romantizado, de atores externos a coletivos historicamente subalternizados em lutas desses grupos por garantia de direitos (McKenzie, 2014; Bazzo, 2020).

O pensamento "contracolonizador" de Antônio Bispo dos Santos (2015) acerca das alteridades e seus entrelaçamentos nos adverte que "nem tudo que se ajunta se mistura", assim como "nem tudo que se mistura se ajunta”. Consideradas essas fronteiras, Santos visualiza como possíveis a "confluência”, isto é, a convivência entre diferenças, como também a "transfluência”, que implica sua conjugação, mantida em ambos os movimentos a plenitude particular a cada alteridade em jogo, ou seja, seu valor como diversidade, que não se confunde com recrutamento como desigualdade.

Os textos apresentados a seguir nos dizem desses fluxos, dos seus caminhos mais ou menos fluidos, sinuosos e/ou tempestuosos. Nessa perspectiva, os trabalhos reiteram o valor da etnografia para o aprofundamento dos matizes que atravessam os marcadores sociais da diferença, em seus dilemas e conquistas, no âmbito de discussões, análises, proposições e intervenções, na academia e fora dela.

No artigo de abertura deste número do dossiê, Alef de Oliveira Lima (2021) nos apresenta uma etnografia dos dilemas e das demandas de estudantes transgêneros perante a escolarização moderno-ocidental que, historicamente, confere primazia ao binarismo masculino-feminino, central ao sistema capitalista de produção. Esse binômio de controle social se manifesta opressivamente naturalizado enquanto operador classificatório e, portanto, avaliativo de condutas, relações e trajetórias dentro das instituições de ensino.

Lima conduziu oficinas de pesquisa com discentes do TransEnem, coletivo de educação popular em Porto Alegre (RS), preparatório para provas de admissão em cursos de nível superior, no qual ele atuou como professor de Sociologia. Dessa forma, pôde reunir uma série de dados sensíveis que tensionam a noção de "disforia" como terminologia médica, que diz dos distúrbios psicossociais capazes de acometer indivíduos em desacordo com o gênero que lhes foi atribuído ao nascer. Ao dialogar, conviver e refletir com estudantes trans, o autor nos propicia verificar que a "disforia" - isto é, o mal-estar profundo dessas(es) discentes com as instituições de ensino e com a sociedade em que estas(es) se encontram inseridas(os) - se origina, em definitivo, do ambiente social em que está a escola e não no 
interior do sujeito trans. Ou seja, a disforia se constrói de fora para dentro e não o contrário, invertendo, portanto, a premissa médica.

$\mathrm{O}$ artigo traz ainda uma importante contribuição acerca da posicionalidade de um investigador cisgênero pesquisando com pessoas trans. Sem desconsiderar a bandeira "nada sobre nós sem nós", empunhada pelos movimentos de defesa identitária na contemporaneidade, Lima delineia seu espaço de fala como homem-cis-professor, que convoca outros indivíduos assim identificados a pensarem sobre si mesmos, a partir de um gradiente de privilégios e vulnerabilidades sociais interseccionadas. Essa reflexão coloca-se fundamental à luta por uma escola plenamente diversa, onde devem coabitar docentes e discentes tanto trans quanto cisgêneros.

Raimundo Nonato Ferreira do Nascimento e Marcos Paulo Magalhães de Figueiredo (2021) dão continuidade em seu artigo ao debate no dossiê sobre gênero, sexualidade e as tensas relações desses marcadores de diferença com a escola. Por intermédio de etnografia sediada em uma instituição pública de ensino de Teresina (PI), a dupla evidencia os elementos que compóem um perfil de masculinidade considerado apropriado no ambiente educacional. Perfil este completamente idealizado, para fins normativos, visto que destoa por completo da realidade discente marcada pela diversidade sexual e de gênero.

A chave analítica acionada por Nascimento e Figueiredo para analisar seus dados etnográficos consiste em desvelar a rejeição mais aguda da escola a dois tipos que estariam em extremos opostos numa gama de masculinidades empiricamente possíveis: o estudante que se identifica como heterossexual e se mostra viril em demasia e o estudante que se afirma homossexual e é visto como feminino em excesso. Essa trilha demonstra procedimentos disciplinares semelhantes da gestão escolar em relação a sujeitos que se expressam por orientações sexuais e identidades de gênero díspares e que, a princípio, poderiam ser pensadas como analiticamente incomunicáveis.

Os autores têm claro que estudantes heterossexuais ocupam uma posição de privilégio em relação aos homossexuais. Contudo, sem desconsiderar essa desigualdade verticalizada, querem chamar a atenção para uma "aproximação contingente" (Velho, 1997): o fato de que tanto alunos "muito viris", quanto alunos "deveras femininos" não cumprem todos os requisitos considerados fundamentais à masculinidade tida por ideal, tais como a heterossexualidade, a não violência, a discrição e o comprometimento com o trabalho assalariado. Tal quadro torna a expulsão ou a evasão da escola uma perspectiva no horizonte daqueles discentes que não se encaixam nesses limites, algo passível de ocorrer de formas abrupta e aberta ou compassada e velada.

O artigo de José Ricardo Marques Braga (2021) prossegue explorando no dossiê as vivências escolares cotidianas das juventudes LGBT, sigla para coletivos, hoje sabemos, muito diferenciados, mas que, em comum, militam contra opressões de uma cultura cisheteronormativa, a qual, como já foi dito, tem na escola um espaço de manifestação por excelência. O título do trabalho - "Se aqui é o inferno, eu sou a principal demônia!" - figura, certamente, como um chamariz para nossa leitura. A exclamação é de uma das interlocutoras do autor, cuja etnografia se deu no universo de escolas públicas de Fortaleza (CE). 
Nesses ambientes, situar-se enquanto uma "demônia" diz respeito a processos de subjetivação recheados de ambivalências perante a escola como instituição. Ser "demônia” é se revelar desviante aos olhos da norma. Significa, além disso, desafiar e insurgir-se contra as injustiças, exclusões e violências da norma. Contudo, também se refere à afirmação do direito de usufruir da escola sendo quem se é, tendo acesso a tudo que pode oferecer: não somente a educação formal, mas adicionalmente - e não menos importante - a socialidade intensa que essa entidade comporta para as juventudes.

Nessa esteira, Braga nos evidencia uma relação multifacetada das(os) estudantes LGBT com as instituições de ensino. A escola é, ao mesmo tempo, espaço de sofrimento, mas também e, a despeito disso, lugar de se (re)fazer sujeito de projetos de vida, de redes de relações e de aspirações de futuro (como alguns artigos da edição anterior de nosso dossiê também apontam). Portanto, não somente a escola age normativamente sobre essas(es) jovens; elas(es), igualmente, agem sobre a escola, lembrando-a dia a dia da faceta democrática que marca a história paradoxal dessa instituição, à qual já aludimos aqui. Algo, entretanto, é certo: as juventudes LGBT não querem prescindir da escola, em absoluto, mas a desejam transformada, sem sombra de dúvida.

A partir de uma abordagem interseccional, Ana Profírio (2021) explora as dinâmicas que envolvem uma escola em Maceió (AL) que aderiu a uma política inclusiva de gênero e de sexualidade. Ao longo de um ano, a autora acompanhou o cotidiano das(os) estudantes, centrando sua observação não nas interações em sala de aula, mas no que acontecia nos demais espaços compartilhados, ou seja: no pátio, no ginásio, nos corredores, nos banheiros coletivos e na cantina. Foi seguindo as dinâmicas de sociabilidade nestes diferentes espaços escolares que teve acesso ao coito, como assim era intitulado o grupo por uma das interlocutoras da pesquisa. A partir dele, a pesquisadora pode vislumbrar a grade classificatória que ordena quem integra o núcleo das travas, dos machos, das gays e das rachas.

Também foi graças à estratégia adotada para a realização da pesquisa que Profírio percebeu as ambiguidades em torno da política de inclusão aplicada na escola, bem como sobre a centralidade das resenhas como um modo singular de colocar em operação os processos de racialização nesse âmbito. A própria pesquisadora, aliás, se viu enredada nestas tramas, o que rendeu para este artigo também uma oportuna reflexão sobre a construção da posição da investigadora em campo e, claro, sobre racismo. Também resultou na reflexão sobre as insígnias que permitem dar expressão - ou, pelo contrário, tornar opacas e difusas - as marcas da negritude; naquela escola, notadamente, eram os cabelos que cumpriam essa função.

Embora no título do artigo seja dado destaque ao entrecruzamento entre gênero, sexualidade e raça, o trabalho de Profírio também traz elementos para pensarmos sobre a religião como um importante marcador de diferenças nos contextos pedagógicos. Muitas das tensões, mas também dos arranjos inclusivos que aconteciam na escola, ocorriam no âmbito do Juventude para Cristo (JPC), grupo que se reunia periodicamente para promover atividades religiosas nos intervalos entre as aulas. O grupo de orientação cristã (que agrega, portanto, tanto estudantes católicos quanto evangélicos) parece, pois, condensar a complexidade das relações observadas naquele contexto.

Por um lado, o JPC abriga alunas(os) gays, permitindo a estas(es) jovens a vivência de sua religiosidade - algo que parece não ser tão comum, dado que em outros espaços religiosos convencionais há 
menos abertura à inclusão de pessoas LGBT - associada à relativa tolerância ao exercício de identidade de gênero não normativa. O JPC mostra-se, assim, muitas vezes compatível com as premissas inclusivas que norteiam, de modo geral, a pedagogia da escola. Por outro lado, Profírio mostra que o exercício da liderança no interior do grupo - e a partir dele, no colégio como um todo - podia ganhar impulso, ou, pelo contrário, encontrar entraves, à medida que as vivências que interseccionam gênero, sexualidade, classe e raça se aproximavam ou se afastavam de certos parâmetros compartilhados pelas(os) alunas(os). Assim, as "saídas do armário" ou as "transições de gênero" não se faziam sem gerar tensões e exclusões, desestabilizando as práticas de inclusão preconizadas na escola.

O artigo de Judit Gomes da Silva (2021), por sua vez, nos apresenta uma etnografia dos mecanismos de reconhecimento de pessoas autodeclaradas negras e indígenas para ingresso estudantil, via ações afirmativas, em cursos de graduação da Universidade Federal de Santa Catarina (UFSC). Entre o trabalho de campo in loco e aquele realizado com suporte de documentos, a autora cobre um período temporal seis anos, de 2012 a 2018, intervalo no qual o Conselho Universitário da UFSC - o "outro" de pesquisa da etnógrafa - deliberou a respeito de suas políticas de cotas para promoção de direitos de minorias políticas, especialmente quanto à pertinência das comissões de validação de autodeclaração.

Silva descreve uma série de reuniões capitaneadas por essa instância, analisando como emergiram nesse espaço tensões, dissensos e acordos. Nesse contexto, a autora esmiúça o laborioso processo de negociação em meio a uma diversidade de atores que compõem o Conselho, entre gestores universitários, docentes, funcionários, discentes e representantes da sociedade civil. Em tal senda, a etnografia revela que estudantes autodeclaradas(os) negras(os) e indígenas, embora compartilhassem a causa das ações afirmativas, nem sempre concordavam a respeito dos procedimentos pelo qual elas seriam operacionalizadas.

A percepção dessa divergência, logo, nos disponibiliza uma interessante reflexão na interface raça-etnia, enquanto marcadores sociais da diferença. Afora isso, importa notar que se o texto contribui a uma Antropologia da Educação, do mesmo modo instiga debates em uma Antropologia do Estado, demonstrando que, embora a divisão em subcampos disciplinares tenha eficiência heurística, é da hibridez de fato existente entre eles que o conhecimento de valor se faz. Por fim, o investimento da autora em uma sólida etnografia de documentos, não apenas impressos, mas também audiovisuais, constitui certamente uma inspiração para o momento de pandemia da Covid-19, que nos exige distanciamentos interpessoais e convoca a repensar o tradicional trabalho de campo presencial.

Dando sequência à discussão mais específica sobre raça como marcador de diferença, Rosenilton Silva de Oliveira e Leticia Abílio Nascimento (2021) retomam a já clássica discussão sobre os desafios da implementação da Lei 10.639/2003 no âmbito da Educação Básica. De modo a compreender como os pressupostos de uma educação antirracista são colocados em ação, os autores se debruçam sobre as ações pedagógicas que circundam a celebração do Dia da Consciência Negra, tendo como referência o trabalho de pesquisa efetuado em duas escolas públicas localizadas no município de São Paulo (SP).

Em uma delas, a que integra a rede municipal de ensino, os projetos relativos à temática das relações étnico-raciais mostram-se pouco integrados ao currículo escolar. Sob a evocação de uma noção de "autonomia discente", tais iniciativas se desenvolvem, na avaliação dos pesquisadores, sem uma neces- 
sária articulação pedagógica; configuram-se, desta forma, como ações tópicas, cujos resultados, apesar dos propósitos democráticos que tais intervenções pedagógicas mobilizam, ficam aquém das expectativas das políticas públicas que visam à equidade racial e à valorização da diversidade. Já na Escola de Aplicação da Universidade de São Paulo a dupla de pesquisadores encontra uma situação um tanto diversa: uma intensa programação de atividades acompanha docentes e discentes ao longo de todo o calendário letivo, sugerindo maior incorporação dos conteúdos étnico-raciais à experiência escolar cotidiana, bem como maior capacidade de mobilização de princípios de uma educação antirracista.

Em suma, as experiências observadas em ambas as escolas já não podem ser meramente enquadradas sob a rubrica da "pedagogia do evento" (Bakke, 2011). Oliveira e Nascimento indicam, portanto, avanços em relação à situação descrita por Bakke tendo por o cenário os anos finais da década de 2000 e reiteram a necessidade de se considerar as múltiplas gradações no modo como a Lei 10.639/2003 é aplicada. Mas talvez o grande achado desta pesquisa seja o de nos mostrar como o fluxo Universidade-Escola é vital para conformar novas relações de ensino e de aprendizagem e dar mais efetividade à aplicação das políticas educacionais inclusivas. Em tempos em que se multiplicam as suspeitas sobre a relevância do ensino público articulado à pesquisa e à extensão universitárias, o artigo faz alusão à potência das ações desenvolvidas pela academia em associação com as escolas da rede estatal.

O tema do ensino de conteúdos étnico-raciais foi também explorado por Ana Carolina Vaz e Lilian Sagio Cezar (2021). Neste caso, toma-se como objeto de reflexão as ações de educação formal dedicadas à História e Cultura Afro-Brasileira e Indígena, tendo como referência uma escola pública da rede municipal de ensino na cidade de Armação dos Búzios (RJ). A particularidade desta escola é que ela está localizada na comunidade remanescente de quilombo da Rasa.

Neste estudo de caso, as autoras exploram as ações da docente Bianca e de sua turma do quinto ano de Ensino Fundamental na rotina de ensino e de aprendizagem de conteúdos previstos nas Leis $\mathrm{n}^{\circ}$ 10.639/2003 e 11.645/2008. A promoção de um evento literário por parte da Secretaria Municipal de Educação, Ciência e Tecnologia do município de Armação dos Búzios funcionou como estopim para a professora de História propor à turma uma "pesquisa de campo", levando as(os) estudantes até as pessoas mais velhas da comunidade quilombola para que elas pudessem ser entrevistadas. Os registros desta experiência pedagógica foram depois materializados em maquetes, expostas ao público da cidade por ocasião da Festa Literária.

O projeto de Bianca mostrou-se, pois, bastante complexo, pois envolvia: a) tensionar aquilo que é compreendido como a "história oficial"; b) desnaturalizar as relações de desigualdade social que marcam a comunidade; c) valorizar o saber tradicional; d) combater o preconceito em relação à comunidade quilombola e a seus moradores; e) levar a comunidade à escola (tanto por meio da exploração das narrativas locais, ora transformadas em conteúdo escolar, como por meio da visita dos moradores da cidade à exposição de maquetes). A combinação de tantos objetivos, educativos e políticos, se liga à própria condição de Bianca: casada com um membro da comunidade da Rasa e ali vivendo, a docente desenvolveu uma atenção especial para a história local, assumindo ser premente a difusão dos conhecimentos "dos mais velhos" junto aos mais jovens. Também se antevê, em rápida passagem do artigo, sua 
percepção sobre os perigos iminentes de se perder esta memória, inclusive por efeito de novas dinâmicas religiosas que requalificam, negativamente, as práticas associadas à ancestralidade africana.

$\mathrm{O}$ artigo tangencia, assim, a discussão sobre a escola como um lugar estratégico para a produção de uma memória coletiva, sendo também, por consequência, terreno de intensa disputa, quer pelas tradições, quer pelas representações étnico-raciais. Em sua abordagem ao tema as autoras privilegiam, contudo, a produção de um relato sobre a experiência didática, indicando as potencialidades da ação de Bianca, o que alinharia sua prática pedagógica à perspectiva decolonial.

No texto que encerra este número do dossiê, Sandra Pereira Tosta, Wesley Lopes da Silva e Lucimara A. L. Costa (2021) retomam a religião como marcador da diferença, lançando olhares sobre as performances corporais de estudantes declaradamente evangélicos. $\mathrm{O}$ foco da pesquisa recai sobre discentes vinculados à Igreja Assembleia de Deus, uma das denominações pentecostais mais antigas do Brasil e com orientações mais específicas sobre a conduta corporal de seus membros. A observação das aulas de Educação Física realizadas em uma escola estadual localizada na zona rural de Minas Novas (MG) e o conjunto de anotações feitas por treze estudantes assembleianos, matriculados no Ensino Fundamental e no Ensino Médio do referido colégio, constituem a matéria do artigo do trio de autores.

O manuscrito se soma, assim, à literatura que vêm explorando as relações entre religião e educação, destacada na seção anterior. No contexto analisado por Tosta, Silva e Costa, o comportamento em sala e na quadra esportiva guarda, de modo geral, parentesco com a disciplina aprendida pelos(as) estudantes nos bancos da igreja. $\mathrm{O}$ artigo investe em mostrar como as marcas de distinção como fiéis assembleianas(os) são mantidas no âmbito da escola, especialmente entre as moças, às quais são reservadas prescrições aparentemente mais severas sobre o comportamento público que aquelas que incidem sobre os rapazes.

Porém, ainda que vestimentas, maquiagem e penteados prescritos sejam, de modo geral, adotados pelas alunas e, portanto, a lógica religiosa oriente as condutas corporais, isso não significa que não haja, por parte das e dos estudantes, algum manejo das regras de conduta incorporadas na comunidade de fé. Os preceitos doutrinários são, assim, passíveis de serem relativizados, favorecendo adaptações especialmente por parte das(os) que se engajam nas práticas esportivas e lúdicas promovidas na escola. O artigo também faz alusão a como estes corpos evangélicos não são inertes: eles ganham movimento em circuitos próprios de lazer promovidos pela igreja, tornando-a centro ativo da promoção de uma sociabilidade juvenil.

Finalizamos esta apresentação agradecendo, uma vez mais, a Caroline Leonardi de Quadros pela produção da ilustração da capa desta edição, a partir de fotografia gentilmente cedida por Alef de Oliveira Lima de um zine produzido por interlocutores(as) de sua pesquisa. Que a potência desta imagem traduza a complexidade dos jogos de alteridade acompanhados por autoras e autores em suas incursões, sob inspiração etnográfica e em meio a diferentes contextos pedagógicos, de Norte a Sul no país, gerando contribuições que temos a honra de editar aqui na Campos.

Desejamos a todas(os) uma boa leitura! 
Eva Scheliga é Doutora em Ciência Social (Antropologia Social) pela Universidade de São Paulo (USP) e Professora Adjunta da Universidade Federal do Paraná(UFPR).

Juliane Bazzo é Doutora em Antropologia Social pela Universidade Federal do Rio Grande do Sul (UFRGS) e pesquisadora associada ao grupo ¿DiVerso?: pesquis(ações) sob(re) resistências sociais, da Universidade Federal da Grande Dourados (UFGD).

\section{REFERÊNCIAS}

Almeida, H. B. de et al. (2018). Numas, 10 anos: um exercício de memória coletiva. In: G. S. R. Saggese et al. (org.). Marcadores sociais da diferença: gênero, sexualidade, raça e classe em perspectiva antropológica (pp. 9-30). São Paulo: Terceiro Nome, Editora Gramma.

Akotirene, C. (2018). O que é interseccionalidade? Belo Horizonte: Letramento.

Bakke, R. R. B. (2011). Na escola com os orixás: o ensino das religiões afro-brasileiras na aplicação da Lei 10.639 (Tese de Doutorado). Programa de Pós-Graduação em Antropologia Social, Universidade de São Paulo, São Paulo. http://www.teses.usp.br/teses/disponiveis/8/8134/tde-31052012-160806/ pt-br.php

Bazzo, J. (2020). Não tenho filhos. Posso ser aliada da maternidade? Catarinas, 10 maio. Disponível em: <https://catarinas.info/>. Acesso em: 18 mai. 2021.

Bazzo, J., \& Scheliga, E. (2020). Etnografias em contextos pedagógicos: alteridades, agências e insurgências. Campos - Revista de Antropologia, 21(2), 11-27. http://dx.doi.org/10.5380/cra.v21i2.79672

Braga, J. R. M. (2021). “Se aqui é o inferno, eu sou a principal demônia!”: etnografando itinerários juvenis LGBT em contextos escolares de Fortaleza/CE. Campos - Revista de Antropologia, 22(1), 69-91.

Braga, L. G. (2008). Na lei e nas escolas: diferentes aspectos do ensino religioso no Estado do Rio de Janeiro. Debates do NER, 14, 69-87. https://doi.org/10.22456/1982-8136.7281

Butler, J. (2017). Quem tem medo de falar sobre gênero? TV Boitempo, 08 nov. Disponível em: <https://www.youtube.com/channel/UCzwfw0utuEVxc4D6ggXcqiQ>. Acesso em: 18 mai. 2021.

Campos, R. B. C.; Paiva Jr., G. S.; Silva, J. C. L. E.; Medeiros, S. G., \& Cisneiros, Paula N. (2010). Pesquisando o invisível: percursos metodológicos de uma pesquisa sobre sociabilidade infantil e diversidade religiosa (2009). Teoria \& Sociedade, 17, 148-175. 
Campos, R. B. C., \& Silva, J. C. L. E. (2011). Quando eu crescer, eu vou escolher a minha religião!? A reinvenção da religião dos brasileiros através do olhar infantil. Interseçôes, 13, 278-303. https:// www.e-publicacoes.uerj.br/index.php/intersecoes/article/view/4616

Capai, E. (2019). Espero tua (re)volta. Brasil, documentário, 90 min.

Carneiro, S. de S. (2014). Ensino religioso no Rio de Janeiro: um bom caso para se pensar religião, direitos humanos e as relações entre Estado e Igreja. Comunicações do ISER, 69, 72-79. https://www. iser.org.br/publicacao/comunicacoes/69/

Carvalho, I. C. M., Medaets, C., \& Mezié, N. (2019). "Uma aula assim muito forte”: aprendizagem, escola e ritual em tempos de ocupação. Psicologia Política, 19(45), 244-260. http://pepsic.bvsalud. org/pdf/rpp/v19n45/v19n45a08.pdf

Crenshaw, K. (2002). Documento para o encontro de especialistas em aspectos da discriminação racial relativos ao gênero. Revista Estudos Feministas, 10(1), 171-188. https://doi.org/10.1590/S0104026X2002000100011

Debert, G. G. (2010). A dissolução da vida adulta e a juventude como valor. Horizontes Antropológicos, 16(34), 49-70. https://doi.org/10.1590/S0104-71832010000200003

Dickie, M. A. S., \& Lui, J. (2007). O ensino religioso e a interpretação da lei. Horizontes antropológi$\cos , 13$ (27), 237-252. http://dx.doi.org/10.1590/S0104-71832007000100011

Diniz, D., Lionço, T., \& Carrião, V. (2010). Laicidade e ensino religioso no Brasil. Brasília: UnB/Letras Livres.

Frigotto, G. (2001). A produtividade da escola improdutiva: um (re)exame das relações entre educação e estrutura econômico-social capitalista. 6 ed. São Paulo: Cortez.

Giumbelli, E. (2009a). Ensino Religioso em Escolas Públicas no Brasil: notas de pesquisa. Debates do NER, 14, 50-68. https://doi.org/10.22456/1982-8136.7280

Giumbelli, E. (2009b). O ensino religioso em sala de aula: observações a partir de escolas fluminenses. Antropolítica, 23, 35-55.

Giumbelli, E. (2011). A religião nos limites da simples educação: notas sobre livros didáticos e orientações curriculares de ensino religioso. Revista de Antropologia, 53, 39-78. https://www.revistas.usp. $\mathrm{br} / \mathrm{ra} /$ article/view/27345

Giumbelli, E., \& Carneiro, S. de S. (2004). Introdução. Comunicações do ISER, 60, 11-19. https:// www.iser.org.br/publicacao/comunicacoes/60/ 
Giumbelli, E., \& Carneiro, S. de S. (2006). Religião nas escolas públicas: questôes nacionais e a situação no Rio de Janeiro. Revista Contemporânea de Educação, 2, 155-177. https://revistas.ufrj.br/index. $\mathrm{php} / \mathrm{rce} /$ article/view/1502

Guedes, S. L. (2014). Por uma abordagem etnográfica dos contextos pedagógicos. In: S. L. Guedes \& T. A. Cipiniuk (org.). Abordagens etnográficas sobre educação: adentrando os muros das escolas (pp. 7-10). Niterói: Alternativa.

Knoblauch, A. (2015). Formação docente e religião. Ciências da Religião, 13, 65-89. http://editorarevistas.mackenzie.br/index.php/cr/article/view/8888

Lima, A. O. (2021). Tristeza, disforia e bem-estar: perspectivas etnográficas sobre a escolarização das pessoas trans. Campos - Revista de Antropologia, 22(1), 33-48.

Lui, J. de A. (2007). Entre crentes e pagãos: ensino religioso em São Paulo. Cadernos de Pesquisa, 37(131), 333-349. https://doi.org/10.1590/S0100-15742007000200006

Mak, D. (2014) A presença da religião em ações docentes de uma escola pública de educação infantil (Dissertação de Mestrado em Educação). Pontifícia Universidade Católica de São Paulo, São Paulo.

Maia, B. (2014). "Matéria de caderno": jocosidade e evitação nas aulas de ensino religioso em uma escola pública. In: T. Cipiniuk \& S. L. Guedes. (orgs.). Abordagens etnográficas sobre educação: adentrando os muros das escolas (pp. 163-183). Niterói: Editora Alternativa/FAPERJ.

Massignon, B. (2000). Laïcité et gestion de la diversité religieuse à l'école publique en France. Social Compass, 47(3), 353-366. https://doi.org/10.1177/003776800047003005

McKenzie, M. (2014). Black girl dangerous: on race, queerness, class and gender. Oakland: BGD Press. Mello, A. G. de. (2019). Olhar, (não) ouvir, escrever: uma autoetnografia ciborgue (Tese de Doutorado). Universidade Federal de Santa Catarina, Florianópolis.

Minarelli, M. N. (2020). Educação e religiosidade evangélica nos meios populares: expectativas das familias sobre escolarização e educação moral (Dissertação de Mestrado). Faculdade de Educação, Universidade Estadual de Campinas, Campinas.

Miranda, A. P. M. (2015). "Motivo presumido: sentimento": identidade religiosa e estigmatização escolar no Rio de Janeiro. Dilemas, 1, 139-164. https://revistas.ufrj.br/index.php/dilemas/article/ view/7319

Miranda, A. P. M., \& Maia, B. (2014). Ensinar religião ou falar de religião? Controvérsias em escolas públicas do Rio de Janeiro. Revista Teias, 14, 80-97. https://www.e-publicacoes.uerj.br/index.php/ revistateias/article/view/24385 
Miskolci, R. (2021). Batalhas morais: politica identitária na esfera pública técnico-midiatizadora. Belo Horizonte, São Paulo: Autêntica Editora.

Nascimento, R. N. F., \& Figueiredo, M. P. M. de. (2021). Ações e reações da escola diante de masculinidades hegemônicas e não hegemônicas: um olhar antropológico. Campos - Revista de Antropologia, 22(1), pp. 49-68

Oliveira, R. S. de, \& Nascimento, L. A. (2021). "Pedagogia do evento": o dia da consciência negra no contexto escolar. Campos - Revista de Antropologia, 22(1), 135-158.

Pereira, A. B. (2017). Do controverso "chão da escola" às controvérsias da etnografia: aproximações entre antropologia e educação. Horizontes Antropológicos, 23(49), 149-176. https://doi.org/10.1590/ s0104-71832017000300006

Profírio, A. (2021). É inclusão, com exclusão? Sobre os entrecruzamentos de gênero, raça e sexualidade no espaço escolar. Campos - Revista de Antropologia, 22(1), 92-110.

Ranquetat Jr., C. (2008). Educação e religião: o novo modelo de ensino religioso nas escolas públicas do Estado do Rio Grande do Sul. Debates do NER, 14, 111-133. https://doi.org/10.22456/19828136.7282

Rede Escola Pública e Universidade. (2019). Produção do conhecimento e a luta contra a barbárie na educação. In: F. Cássio (org.). Educação contra a barbárie: por escolas democráticas e pela liberdade de ensinar (pp. 193-198). São Paulo: Boitempo.

Rodrigues, E. (2015). Formação de professores para o ensino de religião nas escolas: dilemas e perspectivas. Ciências da Religião, 13, 19-46. http://editorarevistas.mackenzie.br/index.php/cr/article/ view/8886

Sallas, A. L. F. (2017). E a luta continua! \#ocupatudo: potência e dilemas da ação política. Interseções, 19(2), 463-482. https://doi.org/10.12957/irei.2017.32021

Santos, A. B. dos. (2015). Confluências x Transfluências. In: Colonização, Quilombos: modos e significados (pp. 89-104). Brasília: INCTI, UnB, Programa INCT, CNPq, MCTI.

Santos, M. S. dos. (2016). Religião e demanda: o fenômeno religioso em escolas públicas (Tese de Doutorado). Instituto de Filosofia e Ciências Humanas, Universidade Estadual de Campinas, Campinas.

Scheliga, E. L.; Knoblauch, A., \& Bellotti, K. K. (2020). Vínculos religiosos entre estudantes universitários: comparações entre licenciatura e bacharelado. Educar em revista, 36, e72695. https://doi. org/10.1590/0104-4060.72695 
Silva, A. (2019). O que aprendi (e o que não aprendi) na escola. In: F. Cássio (org.). Educação contra a barbárie: por escolas democráticas e pela liberdade de ensinar (pp. 187-192). São Paulo: Boitempo.

Silva, J. G. da. (2021). Disputas por modos de reconhecimento em políticas afirmativas no Ensino Superior brasileiro. Campos - Revista de Antropologia, 22(1), 111-134.

Silva, L. F. da. (2019). Escola pública e pentecostalismos: distância territorial, dinâmica religiosa e sociabilidade no espaço escolar (Tese de doutorado). Programa de Pós-Graduação em Ciências Sociais, Universidade Federal de Juiz de Fora, Juiz de Fora.

Silva, M. E. (2011). Diversidade religiosa na escola pública: um olhar a partir das manifestaçôes populares dos ciclos festivos (Dissertação de Mestrado). Programa de Pós-graduação em Antropologia, Universidade Federal de Pernambuco, Recife.

Silva, M. E., \& Campos, R. B. C. (2011). Ciclos festivos na escola pública e pluralismo religioso: conflitos e interações - um ensaio por uma abordagem teórico-metodológica do estudo da festa no espaço escolar. Revista FAEEBA, 20, 31-40.

Simões, J. A. (2018). A dinâmica do campo: temas, tendências e desafios. In: D. Simião \& B. Feldman-Bianco (org.). O campo da antropologia no Brasil: retrospectiva, alcances e desafios (pp. 57-82). Rio de Janeiro: Associação Brasileira de Antropologia.

Souza, A. J. B. de. (2016). “Tia, o que é religião?”. Religião, moral e corpo entre crianças na cidade mais evangélica do Brasil (Dissertação de Mestrado). Programa de Pós-graduação em Antropologia, Universidade Federal de Pernambuco, Recife.

Strathern, M. (1980). No nature, no culture: the Hagen case. In: C. MacCormack \& M. Strathern (eds). Nature, culture and gender (pp. 174 - 222). Cambridge: Cambridge University Press.

The Intercept. (2019). Os três pilares da ocupação - CPII. Disponível em: https://www.youtube.com/ channel/UCNqzAD9EiECreuH6LA8IYeA. Acesso em: 18 mai. 2021.

Therborn, G. (2010). Os campos de extermínio da desigualdade. Novos Estudos, 87, 145-156. http:// dx.doi.org/10.1590/S0101-33002010000200009

Tosta, S. P., Silva, W. L da, \& Costa, L. A. L. (2021). Religião e performances corporais: etnografia com alunos evangélicos da zona rural de uma escola pública de Minas Gerais. Campos - Revista de Antropologia, 22(1), 184-213.

Turner, V. (2008 [1974]). Dramas, campos e metáforas: ação simbólica na sociedade humana. Niterói: Editora da Universidade Federal Fluminense. 
United Nations Human Rights. Office of the High Commissioner. (2017). OL BRA 04/2017. Disponível em: http://www.ohchr.org. Acesso em: 13 abr. 2017.

Valente, G. (2015). A presença oculta da religiosidade na prática docente (Dissertação de Mestrado). Faculdade de Educação, Universidade de São Paulo, São Paulo.

Vaz, A. C., \& Cezar, L. S. (2021). Tradição oral, construção de diálogo e conhecimento na comunidade quilombola da Rasa. Campos - Revista de Antropologia, 22(1), 159-183.

Velho, O. (1997). Globalização: antropologia e religião. Mana, 3(1), 133-154. https://doi. org/10.1590/S0104-93131997000100005 


\section{ETNOgRAFias EM CONTEXTOS PEDAgógicos: ALTERIDADES EM JOGO}

Resumo: Este texto almeja um debate sobre e, ao mesmo tempo, com o segundo conjunto de artigos do dossiê Etnografias em contextos pedagógicos, cujo foco dirige-se à problematização de diacríticos de alteridade nos ambientes formais de ensino. Situamos esse apanhado de manuscritos em um contexto de incremento no Brasil, a contar da primeira década de 2000, de estudos antropológicos hospedados em linhas de pesquisa a versar acerca dos marcadores sociais da diferença. Argumentamos que, não coincidentemente, esse crescimento incide sobre uma Antropologia da Educação contemporânea que toma as instituições de ensino, tensos e expressivos reservatórios de alteridade, enquanto universos de investigação. Instigadas pelas discussões que os artigos nos suscitam, exploramos duas temáticas que nos são caras enquanto frentes particulares de pesquisa - a Primavera Secundarista e a religiosidade nos espaços escolares -, por acreditar que ambas nos possibilitam evidenciar, empiricamente, a ambivalência entre subalternização e insurgência intrínseca à educação formal moderno-ocidental, oscilação em que as diferenças, historicamente, têm exercido papel crucial.

Palavras-chave: Etnografia escolar; Gênero; Sexualidade; Raça; Religião.

\section{ETHNOGRAPHY IN PEDAGOGICAL CONTEXTS: THE OTHERNESS AT STAKE}

Abstract: This text aims a debate about and, at the same time, with the second set of articles of the dossier Ethnographies in Pedagogical Contexts, which focus on the problematization of the otherness in educational institutions. We situate this collection of manuscripts in a context of an increase in Brazil, since the first decade of 2000, of anthropological studies hosted in research lines dealing with social markers of difference. We argue that not coincidentally this growth affects a contemporary Anthropology of Education that takes educational institutions, tense and expressive reservoirs of otherness, as research universes. Instigated by the discussions that the articles raise, we explore two themes that are significant to us as particular research fronts - the Primavera Secundarista (High School Spring) and the religiosity in school spaces - for believing that both allow us to empirically evidence the ambivalence between subalternation and insurgence intrinsic to modern-western formal education, an oscillation in which differences have historically played a crucial role.

Keywords: Schooling Ethnography; Gender; Sexuality; Race; Religion.

RECEBIDO: $31 / 05 / 2021$

AСЕITO: $16 / 06 / 2021$ 